\section{Commentary: Should we attempt to refine an already imperfect nature?}

\author{
Ruggero De Paulis, MD
}

Bicuspid aortic valves are known to be not a simple anatomic malformation but more of a spectrum of a disease that often involves not only the aortic valve but also the ascending aorta. A bicuspid valve represents the fusion of 2 cusps, in the presence or absence of a raphe, with a variable surface distribution. The spectrum of variability in the surface distribution goes from an equal $180^{\circ} / 180^{\circ}$ to as far as $120^{\circ} / 240^{\circ}$, a configuration that resembles that of a tricuspid valve. The phenotypes of a bicuspid valve are so inconsistent that available classifications are still controversial and a source of an ongoing debate. A more recent study has attempted to classify bicuspid aortic valves on the basis of their symmetric or asymmetric presentation. ${ }^{1}$ This should help with more systematic surgical planning, better comparison of results, and improved prognostic evaluation.

Although bicuspid valves might function well for variable periods, there is substantial evidence that symmetric bicuspid valves may perform better and last longer when compared with phenotypes with a more asymmetric configuration. ${ }^{2,3}$ This is the theoretic background behind the strategy of changing the asymmetric bicuspid valve configuration into a more symmetric $180^{\circ} / 180^{\circ}$. A symmetric configuration releases the tension of the fused cusp, allowing a greater effective orifice area with a resulting lower transvalvular gradient. An additional potential benefit is the reduction of the flow eccentricity obtained by reestablishing a more central and laminar flow. A symmetric commissural orientation can be achieved either by plicating the sinus of the conjoined cusps $^{4}$ or by enlarging the sinus of the nonfused cusp ${ }^{5}$; however, root replacement, either with a remodeling or a

From the Department of Cardiac Surgery, European Hospital, Rome, Italy.

Disclosures: Author has nothing to disclose with regard to commercial support.

Received for publication July 1, 2019; accepted for publication July 1, 2019; available ahead of print July 17, 2019.

Address for reprints: Ruggero De Paulis, MD, Department of Cardiac Surgery, European Hospital, Via Portuense 700, 00149 Rome, Italy (E-mail: rdepaulis58@gmail. com).

J Thorac Cardiovasc Surg 2020;160:58-9

$0022-5223 / \$ 36.00$

Copyright (c) 2019 by The American Association for Thoracic Surgery

https://doi.org/10.1016/j.jtcvs.2019.07.009

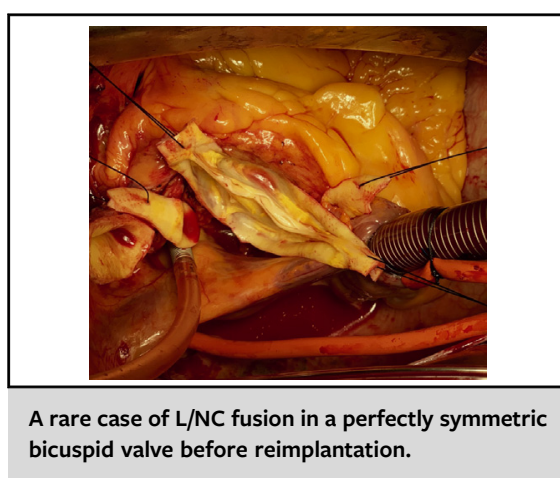

CENTRAL MESSAGE

Symmetric bicuspid valves

appear to function better and

probably longer. The reestablish-

ment of a good symmetry at the

time of valve repair appears

promising, but it is still matter of

controversy.

reimplantation procedure, offers the potential for an easier, more predictable, and more robust way of achieving a symmetric commissural orientation. ${ }^{6}$

In this issue of the Journal, Siki and colleagues ${ }^{7}$ from the University of Pennsylvania show that respecting the $150^{\circ}$ / $210^{\circ}$ degree of asymmetry when reimplanting a bicuspid aortic valve might be equivalent to a more symmetric $180^{\circ} / 180^{\circ}$ orientation. The cutoff value between reestablishing the symmetry and respecting the asymmetry has been fixed at a value of $165^{\circ}$. The first aspect to be underlined is that Siki and colleagues ${ }^{7}$ are probably comparing not only 2 different geometric orientations but also 2 different valve phenotypes, with different natural prognoses. To understand better the role played by different commissural orientations in a more pragmatic way, they should have selected the same asymmetric phenotype (eg, only commissural orientations between $140^{\circ}$ and $160^{\circ}$ ) and then split them into a symmetric or asymmetric commissural orientation. Although the available data show that it is possible to maintain the valve asymmetry and still achieve a good valve competence, this finding does not aid in understanding whether asymmetric valves could perform better and perhaps have a longer life span once their commissural orientation has been made symmetrical. A second aspect to be considered is that even after a 
mean follow-up of 39 months, with only 11 patients at risk at 5 years of follow-up, there was a trend toward higher gradient and higher incidence of postoperative aortic regurgitation in the asymmetric valve group. Considering that the asymmetric valve group also had a higher incidence of severe preoperative aortic insufficiency, we might assume that asymmetry per se could be a predictor of valve failure before and after surgical treatment.

In the end, we are still left with the original question. Can we alter the prognostic implication of asymmetric bicuspid valve phenotypes by modifying their commissural orientation? More time and more data will eventually tell.

\section{References}

1. De Kerkove L, Mastrobuoni S, Froede L, Tamer S, Boodhwani M, van Dyck M, et al. Variability of repairable bicuspid aortic valve phenotypes: towards an anatomical and repair-oriented classification. Eur J Cardiothorac Surg. February 20, 2019 [Epub ahead of print].

2. Aicher D, Kunihara T, Abou Issa O, Brittner B, Gräber S, Schäfers HJ. Valve configuration determines long-term results after repair of the bicuspid aortic valve. Circulation. 2011;123:178-85.

3. Kari FA, Kvitting JP, Stephens EH, Liang DH, Merk DR, Fischbein MP, et al. Tirone David procedure for bicuspid aortic valve disease: impact of root geometry and valve type on mid-term outcomes. Interact Cardiovasc Thorac Surg. 2014; 19:375-81; discussion 381.

4. Schneider U, Schmied W, Aicher D, Giebels C, Winter L, Schäfers HJ. Sinus plication to improve valve configuration in bicuspid aortic valve repair-early results. Ann Thorac Surg. 2017; 103:580-5.

5. Urbanski PP. Repair of bicuspid valve: simple and effective achievement of symmetric valve orientation. J Thorac Cardiovasc Surg. May 31, 2019 [Epub ahead of print].

6. de Kerchove L, Boodhwani M, Glineur D, Vandyck M, Vanoverschelde JL, Noirhomme P, et al. Valve sparing-root replacement with the reimplantation technique to increase the durability of bicuspid aortic valve repair. J Thorac Cardiovasc Surg. 2011;142:1430-8.

7. Siki MA, Habertheuer A, Bavaria JE, Komlo C, Hunt M, Freas MA, et al. Two different geometric orientations for aortic neoroot creation in bicuspid aortic valve repair with root reimplantation. J Thorac Cardiovasc Surg. 2020;160:47-57.
See Article page 47

\section{Commentary: Bicuspid aortic valve geometry - A tale of two valves}

\author{
J. Hunter Mehaffey, MD, MSc, and \\ Robert B. Hawkins, MD, MSc
}

In this issue of the Journal, Siki and colleagues ${ }^{1}$ present an interesting single-institution retrospective study assessing midterm outcomes after valve-sparing root reimplantation (VSRR) with bicuspid aortic valve (BAV). Siki and colleagues ${ }^{1}$ are true experts in aortic valve repair and have been pushing the envelope with regard to salvageable cusp morphology. The bicuspid aortic valve presents the surgeon with a difficult decision in the setting of an aneurysmal aortic root. Traditionally, a Bentall root replacement has been the criterion standard surgery, offering a straightforward, durable repair. VSRR with tricuspid aortic valves has excellent outcomes, however, and its use for bicuspid

\footnotetext{
From the Division of Thoracic and Cardiovascular Surgery, University of Virginia, Charlottesville, Va.

Disclosures: Authors have nothing to disclose with regard to commercial support.

Received for publication July 1, 2019; accepted for publication July 4, 2019; available ahead of print July 18, 2019.

Address for reprints: J. Hunter Mehaffey, MD, MSc, University of Virginia, PO Box 800679, Charlottesville, VA, 22908 (E-mail: jhm9t@virginia.edu).

J Thorac Cardiovasc Surg 2020;160:59-60

$0022-5223 / \$ 36.00$

Copyright (c) 2019 by The American Association for Thoracic Surgery

https://doi.org/10.1016/j.jtcvs.2019.07.005
}

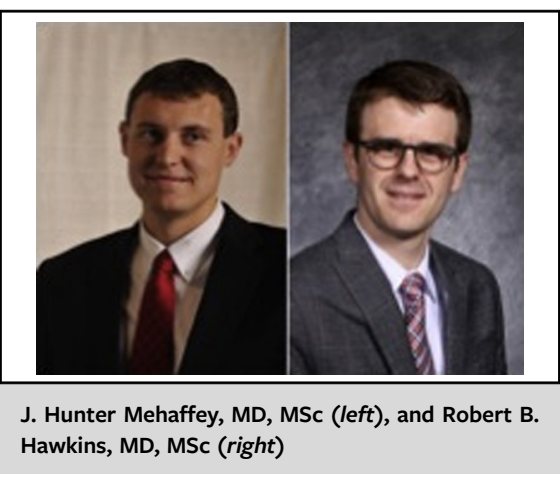

CENTRAL MESSAGE

Valve-sparing root reimplantation is feasible in bicuspid aortic valve, and respecting the geometry may provide the optimal outcomes in the higher-risk Sievers type 1 valves.

valve is starting to gain traction as well., ${ }^{2,3}$ The bicuspid valve offers 2 additional challenges, typically some degree of pathology that needs repair as well as variable morphology and geometry that need to be aligned during reimplantation. Despite these added challenges, this group has previously shown that with careful selection, BAV 